\title{
Pembelajaran Text Preprocessing berbasis Simulator Untuk Mata Kuliah Information Retrieval
}

\author{
Latius Hermawan ${ }^{1}$, Maria Bellaniar Ismiati $^{2}$ \\ Jalan Bangau No.60, UNIKA Musi Charitas, e-mail: tiuz.hermawan@ukmc.ac.id \\ Jalan Bangau No.60, UNIKA Musi Charitas, e-mail: bella@ukmc.ac.id
}

\section{ARTICLE INFO}

Article history:

Received 13 Novomber 2019

Received in revised form 15 January 2020

Accepted 27 January 2020

Available online 31 January 2020

\begin{abstract}
Preprocessing is an important task and step in Information Retrieval. Information Retrieval (IR) is used to decide which documents in a collection must be taken to meet the user's information needs. The comparison is done in 4 steps in preprocessing, namely Case folding, Tokenizing, Filtering, Stemming.

All stages of the preprocessing are done manually during the teaching-learning process. The lecturer explained by writing and explaining one by one the correct words at each stage and students also manually reviewed each stage. Simulator is needed to help solve existing problems. The simulator has been successfully created by displaying 6 menus. The simulator has succeeded in outputting each stage according to the manual theory. From the results of the testing questionnaire, $>90 \%$ of respondents thought that using this simulator made it easier to work on the four stages of text pre-processing so that the time needed also became efficient.
\end{abstract}

Keywords : ir, simulator, text, preprocessing

\section{Pendahuluan}

Preprocessing adalah tugas dan langkah penting dalam Text Mining, Natural Language Processing (NLP) dan Information Retrieval (IR). Di bidang Text Mining, data preprocessing digunakan untuk mengekstraksi pengetahuan yang menarik dan penting serta dari data teks yang tidak terstruktur. Information Retrieval (IR) digunakan untuk memutuskan dokumen mana dalam koleksi yang harus diambil untuk memenuhi kebutuhan pengguna akan informasi [1]. Oleh karena itu, keputusan pengambilan dibuat dengan membandingkan istilah kueri dengan istilah indeks (kata atau frasa penting) yang muncul dalam dokumen itu sendiri.

Perbandingan tersebut dilakukan dalam 4 langkah di preprocessing, yaitu Case folding, Tokenizing, Filtering, Stemming [2]. Dalam kaitannya dalam proses mengajar dalam perkuliahan, semua tahapan preprocessing tersebut dilakukan secara manual saat proses belajar-mengajar. Dosen menjelaskan dengan menulis dan menjabarkan satu per satu kata yang benar di setiap Received November 13, 2019; Revised January 05, 2020; Accepted January 27, 2020 
tahap dan mahasiswa pun melakukan review masing-masing tahapan secara manual pula. Selain itu, pembelajaran dengan cara manual tersebut menjadi monoton dan tidak interaktif antara dosen dan mahasiswa. Hasil dari kuesioner awal yang diberikan kepada mahasiswa yang pernah mendapat materi mengenai text pre-processing mengemukakan bahwa para mahasiswa mengalami kesulitan saat melakukan keempat tahapan pre-processing secara manual karena membutuhkan waktu yang lama untuk pengecekan secara berulang-ulang satu per satu dari masing-masing kata yang akan diproses. Salah satu penyebabnya adalah penulisan ulang setiap contoh kalimat yang ada pada setiap tahap preprocessing text yang membuat bosan para mahasiswa saat menganalisis teks.

Selain kebosanan dan suasana monoton yang dirasakan mahasiswa, hal yang sama juga dialami oleh dosen ketika menjadi pengampu mata kuliah Information Retrieval. Proses preprocessing yang dilakukan secara manual mengakibatkan mahasiswa dan dosen mengalami kendala untuk dapat melakukan preprocessing text secara lebih cepat, akibatnya proses belajar mengajar menjadi tidak efisien. Akibatnya, mahasiswa dan dosen seringkali kehabisan waktu pada saat proses belajar untuk mata kuliah tersebut. Kendala lain yang juga ditemui akibat masalah tersebut adalah penulisan ulang setiap contoh kalimat yang ada pada setiap tahap preprocessing text, dimana terdapat 4 tahapan yang ada yaitu Case folding, Tokenization, Filtering, Stemming.

Salah satu cara untuk mengatasi permasalahan tersebut adalah dengan merancang model pembelajaran yang baik dan interaktif. Tao et al (2011) menyebutkan bahwa alat bantu pembelajaran yang dirancang dengan baik, terbukti secara efektif mengurangi kesulitan dalam mempelajari topik-topik yang kompleks [3]. Dalam penelitiannya [4] menemukan bahwa penggunaan CrypTool sebagai alat bantu pembelajaran kriptografi meningkatkan nilai (grade) mahasiswa hingga 10\% dibandingkan dengan pembelajaran tanpa bantuan CrypTool [4]. Temuan serupa juga diungkapkan oleh Katz (2015), bahwa penggunaan alat bantu (simulator) dalam pembelajaran kriptografi dapat meningkatkan kemampuan mahasiswa untuk menyelesaikan kasus-kasus kriptografi dibandingkan dengan cara manual [5]. Berdasarkan penjelasan di atas, maka peneliti membuat suatu simulator untuk membantu menyelesaikan masalah yang ada dengan judul penelitian Pembelajaran Text Preprocessing berbasis Simulator Untuk Mata Kuliah Information Retrieval.

\subsection{Rumusan Masalah}

Rumusan masalah dari penelitian ini adalah sebagai berikut:

Bagaimana membuat pembelajaran text pre-processing berbasis simulator untuk mata kuliah Information Retrieval agar waktu yang dibutuhkan untuk proses belajar-mengajar menjadi lebih efisien?

\subsection{Tujuan}

Adapun tujuan Penelitian ini adalah sebagai berikut

Untuk membuat simulator pembelajaran text pre-processing di mata kuliah Information Retrieval agar waktu yang dibutuhkan untuk proses belajar-mengajar menjadi lebih efisien.

\subsection{Studi Pustaka}

1. Information Retrieval

Information Retrieval (IR) adalah proses menemukan bahan (biasanya dokumen) dari bersifat terstruktur (biasanya teks) yang memenuhi kebutuhan informasi dari dalam koleksi besar yang disimpan di computer [2]. Information Retrieval System (IRS) merupakan sistem yang digunakan untuk menemukan kembali dokumen yang relevan terhadap kebutuhan user dari suatu kumpulan informasi berdasarkan kata kunci atau keywords atau query dari user. Suatu dokumen yang memiliki rangking yang lebih tinggi daripada dokumen lain akan dianggap lebih relevan terhadap query.

\section{Preprocessing}


Berdasarkan ketidak teraturan struktur data teks, maka proses sistem temu kembali informasi ataupun text mining memerlukan beberapa tahap awal yang pada intinya adalah mempersiapkan agar teks dapat diubah menjadi lebih terstruktur. Tahap Text Preprocessing adalah tahapan dimana aplikasi melakukan seleksi data yang akan diproses pada setiap dokumen. Proses preprocessing ini meliputi (1) case folding, (2) tokenizing, (3) filtering, dan (4) stemming [2].

2. Simulator

Simulasi merupakan proses perancangan model matematis atau logis dari sistem nyata, melakukan eksperimen terhadap model dengan menggunakan komputer untuk menggambarkan, menjelaskan dan memprediksi perilaku sistem [8]. Sedangkan [9] simulasi didefinisikan sebagai sekumpulan metode dan aplikasi untuk menirukan atau merepresentasikan perilaku dari suatu sistem nyata, yang biasanya dilakukan pada komputer dengan menggunakan perangkat lunak tertentu.

3. PHP dan My SQL

PHP (HyperText Preprocessor) adalah sebuah bahasa utama script server-side yang disisipkan pada HTML yang dijalankan di server, dan juga bisa digunakan untuk membuat aplikasi desktop. Menurut [6], dalam bukunya yang berjudul Pemrograman Web Dengan PHP ,menyebutkan bahwa : "PHP merupakan secara umum dikenal dengan sebagai bahasa pemrograman script - script yang membuat dokumen HTML secara on the fly yang dieksekusi di server web, dokumen HTML yang dihasilkan dari suatu aplikasi bukan dokumen HTML yang dibuat dengan menggunakan editor teks atau editor HTML, dikenal juga sebagai bahasa pemrograman server side".

\section{Rapid Application Development (RAD)}

RAD atau pengembangan aplikasi cepat adalah pendekatan berorientasi objek untuk pengembangan system yang meliputi metode pengembangan serta perangkat lunak [7]. RAD dilihat sebagai metodologi pengembangan sistem yang berusaha untuk mengatasi perubahan persyaratan kebutuhan user dan merekomendasikan RAD untuk mengembangkan aplikasi berbasis web. RAD merupakan model proses perangkat lunak yang menekankan pada daur pengembangan hidup yang singkat. Gambar model proses RAD dapat dilihat pada gambar 5 seperti di bawah ini.

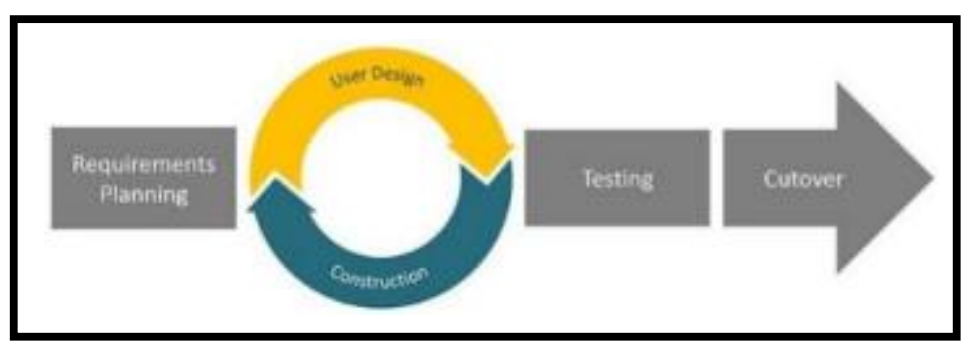

Gambar 1. Rapid Application Development (Sumber : Pressman, 2010)

\subsection{Penelitian Terdahulu}

Penelitian yang dilakukan oleh [10] menggunakan pemrograman Basic mengemukakan bahwa Pada perkuliahan komputer, kriptografi menjadi salah satu mata kuliah yang diajarkan. Pembelajaran kriptografi menjadi sangat penting bagi mahasiswa 
komputer agar mengetahui cara-cara mengamankan data. Proses komputasi dan perhitungan yang rumit membuat mahasiswa mengalami kesulitan menemukan hasil dari enkripsi yang dilakukan. Oleh karena itu penulis akan membuat aplikasi pembelajaran bagi mahasiswa khususnya pembelajaran kriptografi kunci publik ElGamal. Hasil yang diberikan dari penelitian ini yaitu dengan adanya aplikasi ini, mahasiswa dapat mengetahui proses enkripsi dan dekripsi pada algoritma ElGamal secara detail dalam hal proses matematia yang dilakukan. Algoritma ElGamal juga bisa dimanfaatkan untuk mengirimkan sebuah pesan rahasia yang sangat rahasia, yaitu kunci dari sebuah kriptografi simetris. Pada algoritma ElGamal suatu plainteks yang sama akan dienkripsi menjadi cipherteks yang berbeda-beda.

Sedangkan pada penelitian [11] mengatakan dalam penelitiannya menggunakan Java sebagai tool membuat aplikasi bahwa pertumbuhan sosial media yang sangat pesat tidak membuat twitter ditinggal oleh penggunanya. Twitter merupakan sebuah sosial media yang dimanfaatkan oleh penggunanya untuk berbagi informasi. Tidak banyak karakter yang dapat dimasukkan pada komentar di twitter. Keterbatasan karakter tersebut membuat para peneliti memakai data tersebut untuk penelitiannya. Dari uraian tersebut maka diperlukan adanya penanganan yang ekstra pada saat tahap pre-processing atau tahap persiapan data. Pada penelitian kali ini akan membahas beberapa teknik penanganan data komentar dari twitter untuk proses data mining. Hasilnya yaitu setiap proses pada tahap pre-processing data text dari twitter yang telah dibuat, memiliki hasil yang sangat baik, sehingga dapat digunakan untuk penelitian lebih lanjut tentang data mining atau text mining.

Selanjutnya oleh [12] dalam penelitiannya yang berbasis web simulator mengatakan pembelajaran Bahasa Indonesia bagi siswa sekolah dasar amatlah sulit, khususnya mulai kelas satu sampai kelas empat dalam hal pemahaman penalaran kalimat dalam Bahasa Indonesia. Dibutuhkan suatu metode yang dapat mempermudah pemahaman kalimat bahasa Indonesia menggunakan metode maximum marginal relevance. Metode ini dapat mengurangi redudansi dalam perangkaian kalimat pada dokumen dan memiliki lima tahap dalam pencarian text preprocessing yaitu pemecahan kalimat, case folding, tokenizing, filtering, dan stemming. Proses selanjutnya menghitung bobot tf-idf, bobot query relevance dan bobot similarity. Aplikasi ini telah di ujicoba secara acak pada siswa sekolah dasar kelas satu sampai kelas empat. Hasilnya yaitu Aplikasi pembelajaran yang dibuat oleh penulis telah di ujicoba pada 10 siswa sekolah dasar kelas satu sampai kelas empat secara random dengan kesimpulan yaitu: siswa dapat lebih memahami penalaran pelajaran Bahasa Indonesia dengan mudah terutama pada soal essay.

Peneliti [14] juga melakukan penelitian tentang simulasi stemming terhadap kata porno yang berbasis Java yaitu bermulai dari informasi yang mengarah pada isi yang mengandung porno saat ini sangat mudah diterima oleh anak yang masih belum siap menerimanya dari berbagai media diantaranya adalah $\mathrm{CD}$, majalah, televisi, internet, dan lain sebagainya, bahkan di dunia pendidikan baik sengaja atau tidak sengaja mendapat informasi yang mengarah pada pornografi. Maka dalam penelitian ini dikembangkan sebuah aplikasi yang mampu mencegah konten porno pada soal ujian berbahasa indonesia. Aplikasi yang dikembangkan terdiri dari 5 (lima) modul yaitu Tokenizing, Affix Porn Filtering, Stemming, Root Porn Filtering, and Phrase Porn Filtering. Hasil yang didapat yaitu Dalam penelitian ini telah berhasil dibuat sebuah aplikasi text filtering untuk mencegah konten porno pada soal berbahasa indonesia berbasis keyword pada pertanyaan-pertanyaan yang dibuat untuk soal ujian.

\section{Metode Penelitian}


2.1. Tahapan-tahapan penelitian yang dilakukan disesuaikan dengan model Rapid Application

Development (RAD) yang terdiri dari beberapa fase, yaitu :

a. Requirements Planning (Perencanaan Persyaratan)

1. Penentuan masalah di tempat penelitian

2. Penjabaran lebih detail mengenai requirement di tempat penelitian

3. Penyebaran kuisioner untuk mendukung masalah yang dijabarkan di latar belakang penelitian

4. Studi pustaka dan studi literatur sebagai bahan referensi yang dapat mendukung penelitian ini

b. User Design

1. Penentuan tools yang digunakan dalam penelitian ini

2. Perancangan interface untuk Simulator Text Pre-processing

c. Konstruksi

1. Proses coding untuk Simulator Text Pre-processing

2. Pengecekan bug dan error yang masih ada

d. Testing / Evaluasi

1. Pengenalan simulator ke beberapa mahasiswa (36 orang) yang sudah pernah mendapat materi text pre-processing

2. Pengujian simulator ke beberapa mahasiswa (36 orang) yang sudah pernah mendapat materi text pre-processing

3. Pengujian simulator ke beberapa mahasiswa (36 orang) yang sudah pernah mendapat materi text pre-processing

4. Penyebaran dan Pengisian Kuisioner ke responden setelah responden mencoba simulatornya

5. Analisis data hasil kuisioner akhir

6. Pembuatan Laporan Penelitian beserta kesimpulan terhadap hasil penelitian dan pengujian

e. Cutover

Tahap ini merupakan tahap dimana aplikasi sudah siap dipakai saat proses belajar mengajar dilangsungkan sehingga saat proses tidak lagi menggunakan cara manual tetapi menggunakan simulator yang dapat menghasilkan output secara otomatis agar prosesnya menjadi lebih efisien.

2.2. Prosedur perancangan yang dilakukan adalah dengan membuat interface dari Simulator Text Pre-processing. Proses-proses yang dilakukan dalam perancangan interface simulator ini adalah:

1. Proses pembuatan rancangan menu-menu simulator

2. Proses pengumpulan materi-materi yang akan dimasukkan ke dalam simulator text pre-processing

3. Proses coding interface dan fungsionalitas sistem/simulatornya

4. Proses implementasi, yaitu uji coba oleh peneliti untuk mengecek bug dan error sebelum diberikan kepada pengguna dan publik

5. Proses pengujian kepada end user merupakan tahap terakhir yang dilakukan untuk mendapatkan feedback dari pengguna mengenai simulator yang telah dibuat. Pengujian dilakukan kepada beberapa mahasiswa yang sudah pernah mendapat materi mengenai text pre-processing.

6. Setelah end user mencoba simulator, dilakukan proses penyebaran dan pengisian kuisioner ke masing-masing responden

2.3. Metode Pengumpulan data yang digunakan dalam penelitian ini adalah sebagai berikut :

a. Pembagian kuisioner untuk mendukung masalah di latar belakang penelitian 
b. Analisis data hasil kuisioner awal

c. Tinjauan Pustaka (Landasan Teori dan Studi Literatur)

2.4. Analisis data dalam penelitian ini dilakukan dengan perhitungan statistika deskriptif untuk mendapatkan hasil pengujian simulator ini ke 36 mahasiswa UKMC yang sudah pernah mendapat materi mengenai text pre-processing.

\section{Hasil dan Pembahasan}

\subsection{Tampilan Simulator Text Pre-processing}

Alamat website simulator ini adalah http://text-preprocessing indoweb.xyz/. Simulator ini mempunyai 6 menu, yaitu beranda, bantuan, materi, pre test, simulator, dan post test. Masingmasing menu dibuat untuk lebih menjelaskan materi pre-processing dengan lebih detail. Tampilan / interface Simulator Text Pre-processing akan dijabarkan dengan lebih jelas dan lengkap di bawah ini.

\section{Tampilan awal / Menu Beranda}

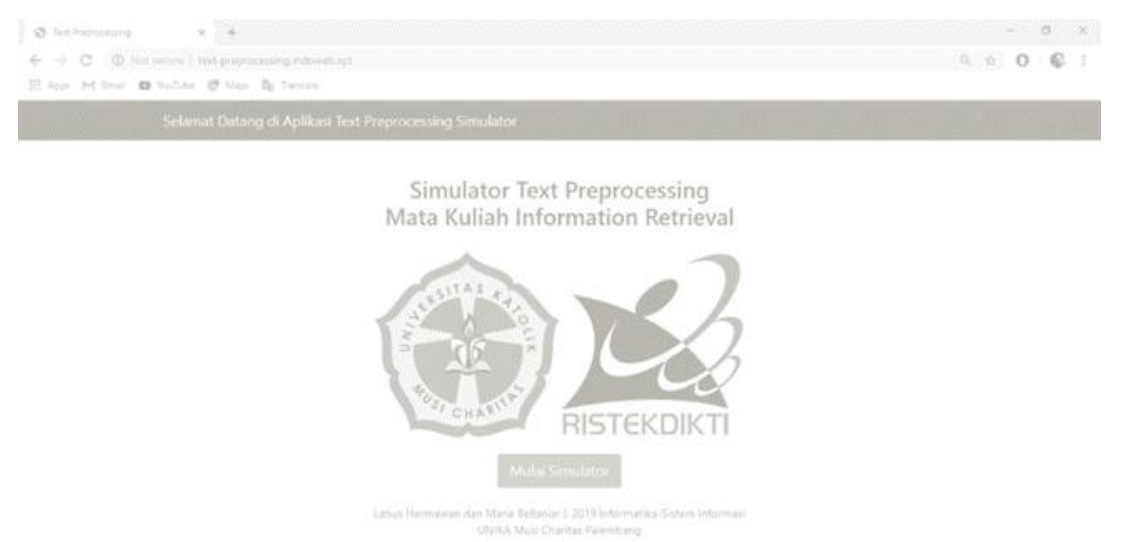

Gambar 6. Tampilan Menu Awal / Beranda

Alamat website dari simulator ini adalah http://text-preprocessing .indoweb.xyz/ dengan menggunakan domain yang tidak berbayar. Tampilan awal berisi judul simulator, logo UKMC, logo RistekDikti, tombol Mulai Simulator, dan nama peneliti. Setelah user mengetahui maksud dan tujuan dibuatnya aplikasi ini, user dapat menekan tombol Mulai Simulator agar dapat langsung masuk ke menu utama, yaitu menu materi untuk mempelajari lebih detail mengenai text pre-processing. Sebelum masuk ke menu materi, sebelumnya akan dijelaskan lebih detail mengenai menu bantuan yang seharusnya dibuka/dibaca terlebih dahulu sebelum memulai menu-menu yang lain.

\section{Tampilan Menu Bantuan}




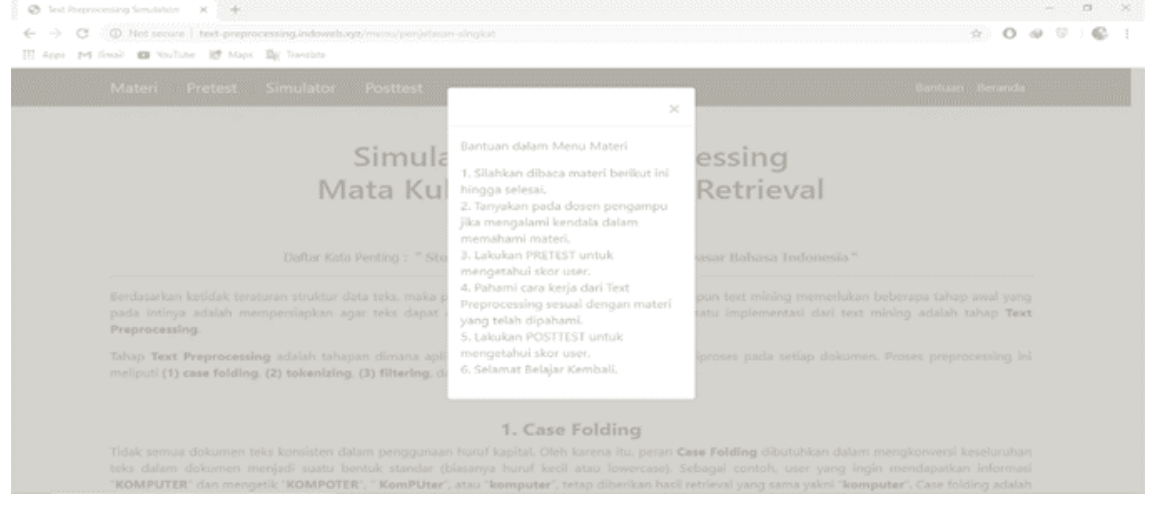

Gambar 7. Tampilan Menu Bantuan

Menu bantuan di atas merupakan menu yang dibuat agar user tidak mengalami kendala saat mengakses simulator text pre-processing. Di dalam menu ini berisi beberapa poin yang menjelaskan menu-menu lain seperti penjelasan pre test dan post test. Oleh karena itu, user sebaiknya mengakses dan membaca menu bantuan ini terlebih dahulu sebelum beralih ke menu-menu lainnya dalam simulator ini.

\section{Tampilan Menu Materi (Tampilan ini sama dengan tampilan ketika user menekan tombol Mulai Simulator)}

Pada menu ini, user diberikan penjelasan mengenai 4 tahapan text pre-processing, yaitu case folding, tokenizing, filtering, dan stemming. Selain berupa tulisan dan contoh, pada bagian ini diberikan pula gambar-gambar yang mendukung untuk masing-masing tahapan. Hal ini dilakukan agar user yang membaca menu materi ini tidak hanya mendapat teori tetapi juga langkah-langkah pastinya dengan menggunakan contoh soal. Selain berupa materi yang dijelaskan secara detail, pada menu ini diberikan pula link untuk melihat daftar kata-kata yang masuk ke dalam stopword dan daftar kata-kata dasar. Link stopword digunakan untuk tahapan filtering sedangkan daftar kata dasar untuk tahap stemming.

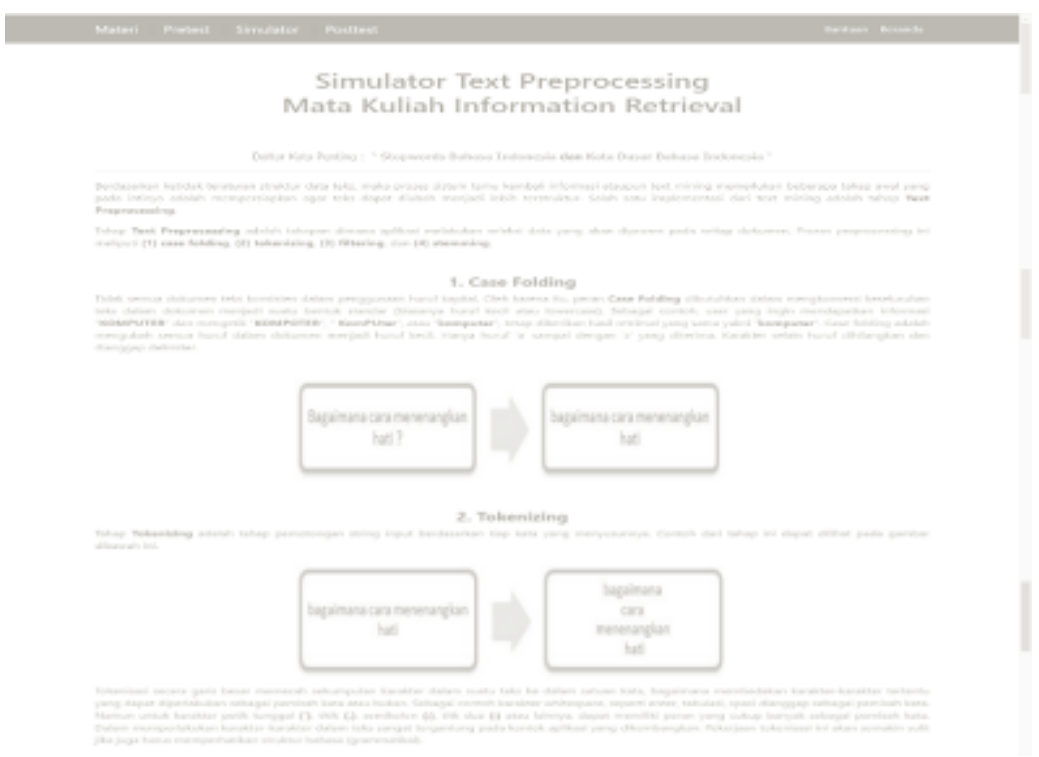

Gambar 8. Tampilan Menu Materi di Simulator 
Gambar 9. Link Stopwords Bahasa Indonesia dan Kata Dasar Bahasa Indonesia

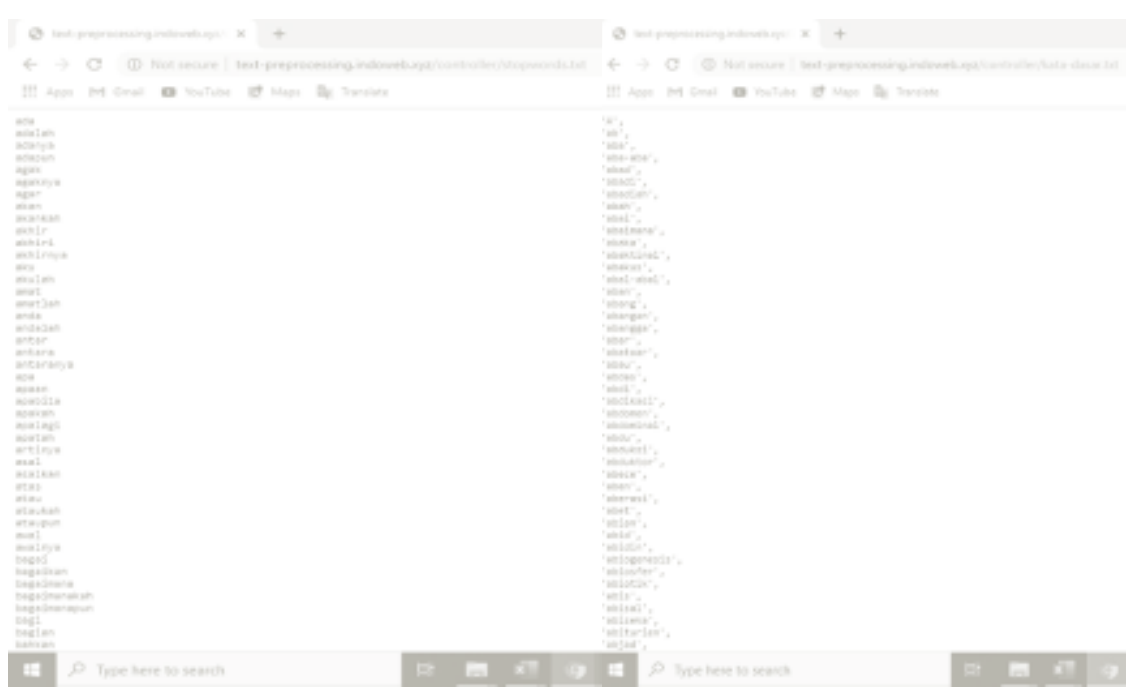

Gambar 10. Contoh Kata yang Masuk ke dalam Stopword

Pada Gambar 10 di atas merupakan daftar kata-kata yang ada di dalam stopword. Apabila dalam suatu kalimat terdapat satu atau lebih kata yang masuk ke dalam daftar stopword, maka kata tersebut harus dihilangkan dari kalimat itu. Kata-kata tersebut dapat dibuang karena dianggap kurang penting (contohnya kata ganti orang, kata sambung, dan masih banyak lagi) karena hasil akhir tahapan text pre-processing hanya akan menghasilkan katakata yang penting saja.

Pada Gambar 10 di atas juga menampilkan daftar kata-kata dasar yang ada di dalam Link Kata Dasar Bahasa Indonesia. Daftar kata dasar tersebut digunakan di tahapan stemming yang merupakan langkah terakhir dalam tahapan text pre-processing. Apabila dalam tahap filtering, masih ada kata yang mempunyai imbuhan dan akhiran, maka dalam tahap ini simulator harus dapat membandingkan kata tersebut dengan daftar kata dasar di link tersebut. Hasil akhir dari text pre-processing adalah berupa kata dasar dan kata-kata yang dianggap penting saja.

\section{Tampilan Menu Pre Test beserta Skor masing-masing Tahapan}

Menu pada Gambar 12 berisi tentang ujian awal sebelum membaca materi ataupun bertanya kepada dosen pengampu sehingga dapat diketahui nilai awal user sebelum masuk ke materi. Contoh menu pre test yang telah diisi ada pada Gambar 13 dan 14 di bawah ini.

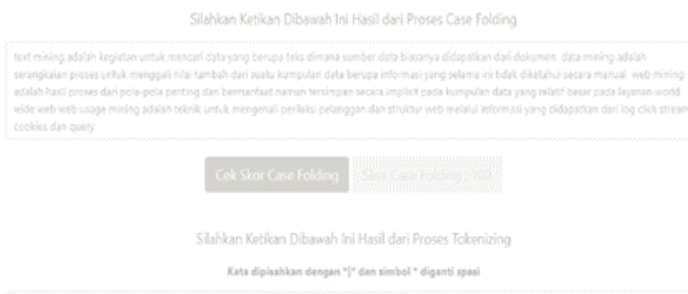


Gambar 13. Skor Case folding dan Tokenizing

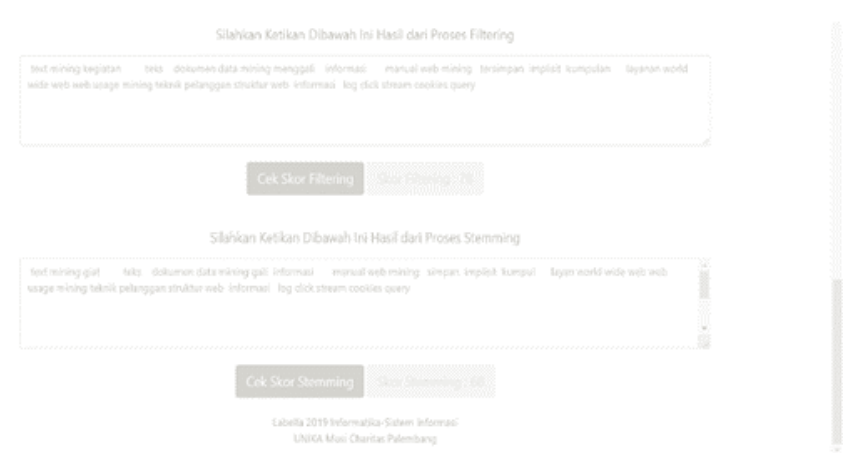

Gambar 14. Skor Filtering dan Stemming

\section{Tampilan Menu Simulator}

Pada Gambar 15 di bawah ini merupakan tampilan menu Simulator yang dapat berulang kali user gunakan dengan kalimat yang bisa berganti-ganti. User memasukkan kalimatnya di bagian kotak putih di bawah tulisan Silahkan Masukkan Text Percobaan. Selanjutnya user dapat menekan tombol case folding, tokenizing, filtering, dan stemming untuk mendapatkan hasil akhir dari text pre-processing.

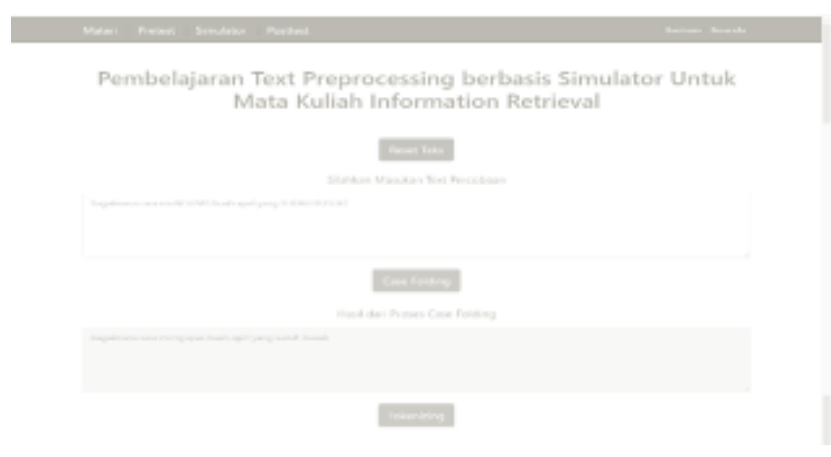

Gambar 15. Tampilan Simulator Text Pre-processing beserta Contohnya

Proses tahapan text pre-processing di simulator ini berjalan dengan baik, yaitu ketika ada suatu kalimat utuh, simulator ini dapat menghasilkan output untuk text pre-processing yang sudah melewati 4 tahapan di atas. Saat user menekan tombol case folding, tampilan kalimatnya sudah dapat merubah semua karakter huruf menjadi huruf kecil dan semua karakter lain seperti tanda baca dan tanda hubung juga sudah dapat dihilangkan oleh simulator ini. Selanjutnya saat user menekan tombol tokenizing, tampilan kalimatnya sudah dibagi-bagi per token/kata yang dipisahkan dengan tanda garis lurus (|). Sampai pada tahap ini, tidak ada kata yang dihilangkan.

TRANSFORMATIKA Vol. 17, No.2, January 2020 : 207-218 
Tahap selanjutnya adalah filtering yaitu menghilangkan beberapa kata yang dianggap kurang/tidak penting berdasarkan stopwords Bahasa Indonesia. Isi dari stopwords contohnya adalah kata ganti orang, kata hubung, dan masih banyak lagi. Apabila kata yang di dalam kalimat tersebut ada di dalam daftar stopwords, maka kata tersebut harus dihilangkan karena sudah dianggap kurang/tidak penting. Pada tahap ini sudah mulai menghilangkan beberapa kata dari keseluruhan kalimat utuh yang dijadikan contoh. Simulator ini sudah berhasil mencocokkan masing-masing kata yang sudah dipisahkan dari tokenizing dengan kata-kata yang ada di dalam stopwords.

Tahap terakhir adalah stemming yaitu tahap menghilangkan semua imbuhan dan akhiran yang melekat di beberapa kata hasil dari filtering. Semua hasil dari stemming, harus berupa kata dasar dan tidak ada lagi imbuhan maupun akhiran yang masih melekat. Prosesnya adalah simulator ini membuang imbuhan dan akhiran dari suatu kata. Setelah itu dibandingkan dengan kata dasar di link kata dasar Bahasa indonesia sehingga didapatkan kata dasar aslinya. Simulator ini sudah berhasil menampilkan kata dasar dari beberapa kata hasil filtering sehingga hasil akhirnya sudah lebih singkat dan berupa kata dasar.

\section{Tampilan Menu Post Test beserta Skor untuk masing-masing Tahapan}

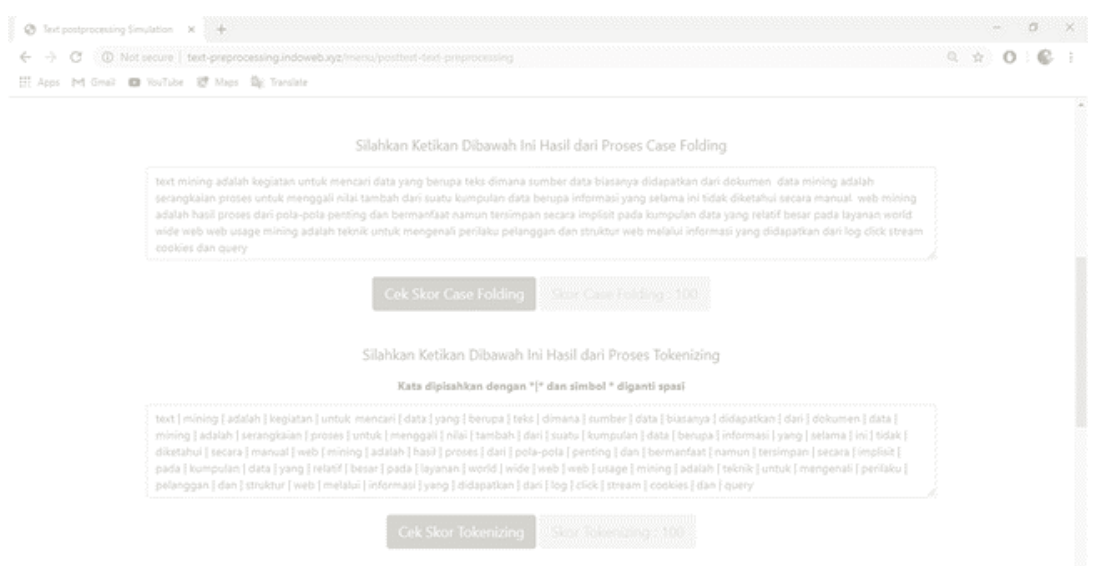

Gambar 19. Skor Case folding dan Tokenizing untuk Post Test

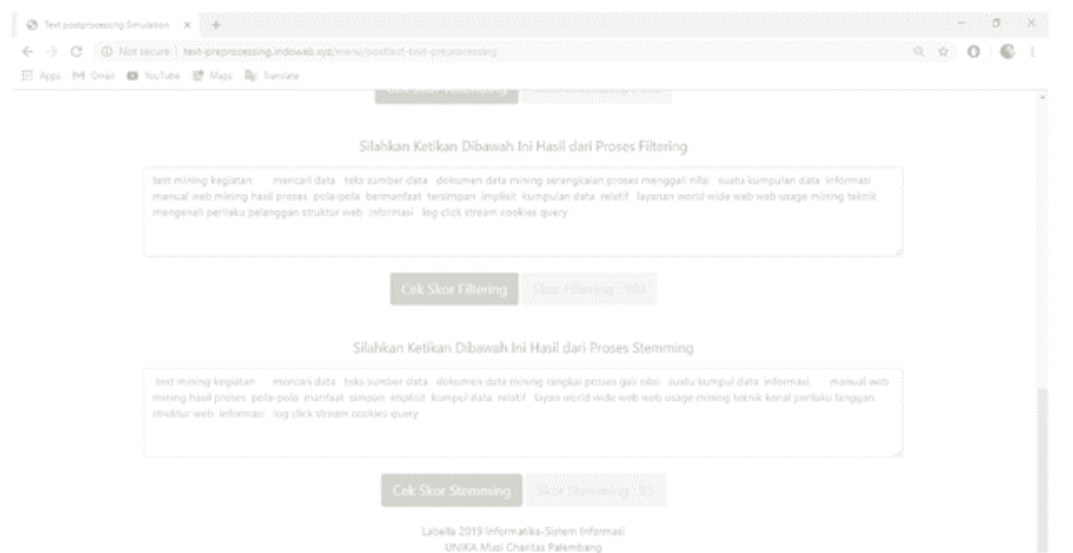

Gambar 20. Skor Case folding dan Tokenizing untuk Post Test

\subsection{Hasil Pengujian Akhir (Kuisioner)}

1. Berdasarkan pengolahan kuisioner terlihat bahwa seluruh mahasiswa tertarik untuk menggunakan simulator edukasi ini dengan persentase sebanyak $100 \%$. Jumlah mahasiswa yang mengisi kuisioner tersebut sebanyak 36 mahasiswa. Hal tersebut menunjukkan bahwa seluruh mahasiswa yang mengisi kuisioner ini tertarik menggunakan simulator ini. 
2. Berdasarkan pengolahan kuisioner terlihat bahwa lebih banyak mahasiswa yang berpendapat bahwa tampilan simulator ini menarik dengan persentase sebanyak $72 \%$ sedangkan masih ada beberapa mahasiswa yang berpendapat bahwa tampilan game edukasi ini tidak menarik dengan persentase sebanyak 28\%. Hal tersebut menunjukkan bahwa hampir seluruh mahasiswa yang mengisi kuisioner ini berpendapat bahwa tampilan simulator edukasi ini menarik.

3. Berdasarkan pengolahan kuisioner terlihat bahwa lebih banyak mahasiswa yang berpendapat bahwa simulator text pre-processing ini mudah digunakan dengan persentase sebanyak $92 \%$ sedangkan masih ada beberapa mahasiswa yang berpendapat bahwa simulator text pre-processing ini tidak mudah digunakan dengan persentase sebanyak $8 \%$. Hal tersebut menunjukkan bahwa hampir seluruh mahasiswa yang mengisi kuisioner ini berpendapat bahwa simulator text preprocessing ini mudah digunakan.

4. Berdasarkan pengolahan hasil kuisioner terlihat bahwa lebih banyak mahasiswa yang berpendapat bahwa fitur pada Simulator ini lengkap dengan persentase sebanyak $75 \%$ sedangkan masih ada beberapa mahasiswa yang berpendapat bahwa fitur pada Simulator ini tidak lengkap dengan persentase sebanyak 25\%. Hal tersebut menunjukkan bahwa hampir seluruh mahasiswa yang mengisi kuisioner ini berpendapat bahwa fitur pada Simulator ini lengkap.

5. Berdasarkan pengolahan hasil kuisioner terlihat bahwa lebih banyak mahasiswa yang berpendapat bahwa tampilan informasi dengan topik pada alur aplikasi simulator telah sesuai dengan persentase sebanyak $97 \%$ sedangkan masih ada beberapa mahasiswa yang berpendapat bahwa tampilan informasi dengan topik pada alur aplikasi simulator tidak sesuai dengan persentase sebanyak 3\%. Hal tersebut menunjukkan bahwa hampir seluruh mahasiswa yang mengisi kuisioner ini berpendapat bahwa tampilan informasi dengan topik pada alur aplikasi simulator telah sesuai.

6. Berdasarkan pengolahan hasil kuisioner terlihat bahwa lebih banyak mahasiswa yang berpendapat bahwa informasi yang disajikan telah sesuai dengan topik dengan persentase sebanyak 94\% sedangkan masih ada beberapa mahasiswa yang berpendapat bahwa informasi yang disajikan tidak sesuai dengan topik dengan persentase sebanyak 6\%. Hal tersebut menunjukkan bahwa hampir seluruh mahasiswa yang mengisi kuisioner ini berpendapat bahwa informasi yang disajikan telah sesuai dengan topik.

7. Berdasarkan pengolahan hasil kuisioner terlihat bahwa lebih banyak mahasiswa yang berpendapat bahwa bahasa yang digunakan dalam simulator ini mudah dipahami dengan persentase sebanyak $83 \%$ sedangkan masih ada beberapa mahasiswa yang berpendapat bahwa bahasa yang digunakan dalam simulator ini tidak mudah dipahami dengan persentase sebanyak $17 \%$. Hal tersebut menunjukkan bahwa hampir seluruh mahasiswa yang mengisi kuisioner ini berpendapat bahwa bahasa yang digunakan dalam simulator ini mudah dipahami.

8. Berdasarkan pengolahan hasil kuisioner terlihat bahwa lebih banyak mahasiswa yang berpendapat bahwa simulator membuat lebih mudah dalam meningkatkan pengetahuan mengenai text pre-processing dengan persentase sebanyak $97 \%$ sedangkan masih ada beberapa mahasiswa yang berpendapat bahwa simulator tidak membuat lebih mudah dalam meningkatkan pengetahuan mengenai text pre-processing dengan persentase sebanyak 3\%. Hal tersebut menunjukkan bahwa hampir seluruh mahasiswa yang mengisi kuisioner ini berpendapat bahwa simulator membuat lebih mudah dalam meningkatkan pengetahuan mengenai text pre-processing. 9. Berdasarkan pengolahan hasil kuisioner terlihat bahwa lebih banyak mahasiswa yang berpendapat bahwa dengan menggunakan simulator dapat lebih terdorong untuk belajar text preprocessing dengan persentase sebanyak $97 \%$ sedangkan masih ada beberapa mahasiswa yang berpendapat bahwa dengan menggunakan simulator, responden tidak dapat lebih terdorong untuk belajar text pre-processing dengan persentase sebanyak 3\%. Hal tersebut menunjukkan bahwa hampir seluruh mahasiswa yang mengisi kuisioner ini berpendapat bahwa dengan menggunakan simulator dapat lebih terdorong untuk belajar text pre-processing.

10. Berdasarkan pengolahan hasil kuisioner terlihat bahwa lebih banyak mahasiswa yang berpendapat bahwa dengan menggunakan simulator mampu memberikan tambahan pengetahuan TRANSFORMATIKA Vol. 17, No.2, January 2020 : 207-218 
mengenai text pre-processing dengan persentase sebanyak $97 \%$ sedangkan masih ada beberapa mahasiswa yang berpendapat bahwa dengan menggunakan simulator tidak mampu memberikan tambahan pengetahuan mengenai text pre-processing dengan persentase sebanyak $3 \%$. Hal tersebut menunjukkan bahwa hampir seluruh mahasiswa yang mengisi kuisioner ini berpendapat bahwa dengan menggunakan simulator mampu memberikan tambahan pengetahuan mengenai text pre-processing.

\section{Kesimpulan}

Kesimpulan yang dapat ditarik dari penelitian ini setelah peneliti berhasil membuat Simulator Text Pre-processing adalah :

Simulator untuk pembelajaran text pre-processing telah berhasil dibuat dengan menampilkan 6 menu, yaitu menu beranda, bantuan, materi, pre test, simulator, dan post test. Simulator ini juga telah berjalan dengan baik karena telah berhasil mengeluarkan output untuk masing-masing tahapan yang sesuai dengan teori manualnya. Dari hasil kuisioner pengujian, > 90\% responden berpendapat bahwa dengan menggunakan simulator ini lebih mempermudah pengerjaan keempat tahapan text pre-processing sehingga waktu yang dibutuhkan juga menjadi efisien.

\section{References}

[1] Gurusamy, V., (2014). Preprocessing Techniques for Text Mining. Conference Paper RTRICS, India

[2] Manning, D. (2008). Introduction to Information Retrieval. Cambridge University Press New York, NY, USA

[3] Tao, J., Ma, J., Mayo, J., Shene, C.-K., \& Keranen, M. (2011). DESvisual: A Visualization Tool for the DES Cipher. Journal of Computing Sciences in Colleges, 27(1), 81-89

[4] Adamovic, S., Branovic, I., (2011). Teaching interactive cryptography: the case for CrypTool. IEEE Conference, ICEST 2011

[5] Zelvina, A., (2012), Perancangan Aplikasi Pembelajaran Kriptografi Kunci Publik ElGamal Untuk Mahasiswa. Jurnal Dunia Teknologi Informasi Vol. 1, No. 1, (2012) 56- 62

[6] Betha Sidik. (2012). Pemrograman Web dengan PHP. Informatika,. Bandung.

[7] Pressman, Roger S. (2010. Software Engineering : A Practitioner's Approach. (7th. Edition). New York: McGraw-Hill Higher Education.

[8] Harrel, C., Ghosh, B.K., dan Bowden, R.O., (2004), Simulation Using Promodel Second Edition, McGraww-Hill; New York.

[9] Hoover, S., dan Perry, R., (1990), Simulation: A Problem Solving Approach, AddisonWesley; Reading-MA

[10] Sulhan, M., (2014)., Metode Stemming Sebagai Preprocessing Pada Filter Kata Porno Melalui Aspek Pendidikan. Seminar Nasional Teknologi Informasi dan Komunikasi, UAJY, Yogyakarta

[11] Mujilahwati, S., (2016)., Pre-Processing Text Mining Pada Data Twitter. Seminar Nasional Teknologi Informasi dan Komunikasi, UAJY, Yogyakarta

[12] Marlinda., L., (2013)., Pembelajaran Bahasa Indonesia Berbasis Web Menggunakan Metode Maximum Marginal Relevance. Seminar Nasional Sistem Informasi Indonesia, Jakarta. 